\title{
Implantação do programa 5S em uma empresa júnior de consultoria
}

\begin{abstract}
Virnna Cristhielle Santana Barbosa

virnnac@gmail.com

Universidade Estadual de Santa Cruz
\end{abstract} (UESC), llhéus, Bahia, Brasil

\section{Meire Ramalho de Oliveira}

meire.oliveira@ufg.br

Universidade Federal de Goiás (UFG),

Aparecida de Goiânia, Goiás, Brasil

\author{
RESUMO
}

A competitividade entre empresas fomenta a necessidade de práticas na gestão da qualidade total para atender de forma efetiva às necessidades de seus clientes e também de seus colaboradores. Uma empresa júnior de consultoria também precisa se manter ativa no mercado. Por esse motivo práticas da qualidade são necessárias. O Programa 5S é considerado uma metodologia apropriada para iniciar e realizar a inserção de programas de qualidade em uma organização, visando melhorias no ambiente de trabalho, aumento de produtividade e gerenciamento de documentos e materiais. O objetivo do estudo é implantar o programa $5 \mathrm{~S}$ em uma empresa júnior de consultoria em uma Universidade Estadual no sul da Bahia. Para tanto, foi necessário analisar o ambiente da empresa e realizar um diagnóstico de suas necessidades além de planejar e executar o Programa 5S, avaliando o processo e sugerindo possíveis melhorias. A implantação do Programa ocorreu em etapas e teve início com a apresentação do tema aos membros, por meio de um workshop, posteriormente os cinco sensos foram colocados em prática e então auditorias periódicas foram realizadas para acompanhar o desenvolvimento dos sensos. Ao fim da execução da primeira auditoria, foi realizada uma pesquisa de satisfação, que identificou que $87,5 \%$ dos membros estavam satisfeitos com a implantação do programa na empresa júnior.
\end{abstract}

PALAVRAS-CHAVE: Gestão da qualidade total. Programa 5S. Empresa Júnior. 


\section{INTRODUÇÃO}

O cenário econômico sugere grande competitividade para o mercado de consultoria, em que atingir o patamar de sucesso implica no atendimento de forma efetiva às necessidades de seus clientes (VIEIRA, et al 2013).

Entre as diversas estratégias adotadas pela indústria na busca de competitividade, encontram-se a implantação dos projetos de melhoria contínua nos processos produtivos e administrativos (TANAKA et al., 2012). Assim, a gestão da qualidade ganha destaque, uma vez que também busca proporcionar o atendimento às necessidades dos seus clientes e colaboradores (VIEIRA et al., 2013).

Nas empresas juniores, a busca pela qualidade e a realidade do cenário competitivo não é diferente, uma vez que possuem a necessidade de conquistar clientes e mercado para garantir a sua sobrevivência (PEREIRA; SILVA; NOVÔA, 2016). Outro ponto a se considerar é que a empresa júnior é formada ainda por não graduados e, portanto, precisa comprovar sua capacidade de atuação no mercado pela máxima dedicação e serviços bem realizados.

As práticas utilizadas para se alcançar a qualidade não estão vinculadas apenas ao sistema de qualidade com base na ISO 9000, e sim no prosseguimento da melhoria contínua, filosofia da gestão da qualidade total. Uma prática utilizada que se associa bem à melhoria da qualidade é o programa 5S (MICHALSKA; SZEWIECZEK, 2007). O Programa 5S é considerado uma metodologia apropriada para iniciar e realizar o processo de qualidade em uma organização (JACA et al., 2012).

Neste estudo, o Programa 5 S foi objeto de análise devido à sua simplicidade e alcance dentro de uma empresa de pequeno porte e com poucos recursos, como é o caso de uma empresa júnior. Os cinco princípios do programa focam na organização eficaz, simplificação do ambiente de trabalho e minimização de desperdícios, melhorando simultaneamente a qualidade e segurança (GUPTA; JAIN, 2015). A empresa júnior objeto deste estudo apresentou problemas na utilização e organização do seu espaço físico limitado, fazendo com que a aplicação do programa fosse justificável e viável.

Deste modo, o presente trabalho tem como objetivo implantar o programa $5 \mathrm{~S}$ em uma empresa júnior de consultoria, em uma universidade estadual localizada ao sul da Bahia. A utilização dessa ferramenta pela empresa júnior de consultoria pode resultar em melhorias no ambiente de trabalho, promoção do bem-estar dos consultores envolvidos, bem como melhorar o controle e uso de documentos, materiais e processos de trabalho.

\section{PROGRAMA 5S}

Esta seção discutirá a Gestão da Qualidade Total e o Programa 5S, detalhando a composição de cada senso.

\section{GESTÃO DA QUALIDADE TOTAL}


Oportunidades podem surgir com a implantação de práticas de melhoria contínua em empresas de pequeno e médio porte, alcançando-se vantagens competitivas, uma vez que essas práticas já são muito comuns em empresas de grande porte (VIEIRA, 2013). Assim, empresas que implantam a gestão da qualidade estão em busca da eficiência organizacional, satisfação dos clientes e desenvolvimento sustentável das organizações (MARSHALL JÚNIOR et al., 2010; KNOREK; OLIVEIRA, 2015).

A gestão da qualidade total (TQM) passou a ser parte do planejamento estratégico de muitas organizações no uso de métodos e ferramentas, e tem como elemento central a melhoria contínua de produtos e processos, com o objetivo final de atender as necessidades dos clientes (JURAN, 1997; OPRIME; MONSANTO; DONADONE, 2010). A TQM utiliza um conjunto de práticas que visa melhorar a produtividade, evitar retrabalhos, rejeições, reclamações dos clientes e desperdícios (BIGLIARDI; GALATI, 2014). Tem-se os seguintes elementos do TQM: liderança e apoio da alta direção na implantação e uso, o relacionamento estreito com os clientes, a gestão dos processos, a gestão da força de trabalho por meio do empowerment, as práticas de seleção e qualificação dos fornecedores, o envolvimento de todas as áreas funcionais no projeto do produto, e fatos e dados de qualidade (CARVALHO; PALADINI, 2005).

A prática com a qual a qualidade será priorizada deve variar de acordo com a organização, adequando-se aos seus objetivos e processos. Existem sistemas de qualidade mais complexos, como a ISO série 9000 (GONZALEZ; MARTINS, 2015) e outros que utilizam ferramentas mais simples, como os cinco sensos, podendo ser inserido numa organização de diferentes formas (MILNITZ e TUBINO, 2016). O importante é que a implantação desses programas ocorra de forma gradual para que a empresa se habitue a mudanças das práticas.

\section{PROGRAMA $5 S$}

Empresas lidam com escassez de recursos diariamente, como falta de espaço adequado, o número de trabalhadores disponíveis, a infraestrutura e instalações, os recursos financeiros para execução dos processos produtivos, entre outros. Para enfrentar algumas limitações, surge o programa 5S, que busca promover alteração comportamental dos colaboradores e mudança de cultura organizacional, auxiliando na melhoria das organizações, comunidades e até mesmo na vida

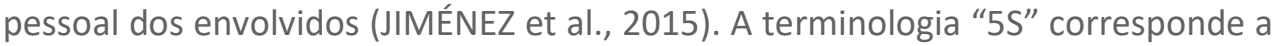
cinco palavras japonesas iniciadas com a letra S, Seiri, Seiton, Seiso, Seiketsu e Shitsuke, que adequando-se as mesmas siglas ao inglês tem-se Sort, Set in Order, Shine, Standardise e Sustain, e mantém o mesmo significado das palavras japonesas: Senso de Utilização; Senso de Ordenação; Senso de Limpeza; Senso de Saude e Higiene e Senso de Autodisciplina. No Brasil, essas palavras foram adaptadas com o termo "senso", mantendo-se a mesma consoante que denomina o programa (JACA et al., 2012; RODRIGUES et al., 2014; KAKKAR et al, 2015)

O Programa 5S foi desenvolvido na década de 1950 por Kaoru Ishikawa e sua equipe, que elaborou uma forma ideal de estabelecer metas e executar ações, que deviam ser atingidas pelas organizações. Ao longo do tempo, a difusão de suas técnicas e conceitos passaram a ser complementadas por outras ferramentas de qualidade, à medida que as necessidades de determinadas organizações evoluíam. 
Embora antiga, é ainda uma ferramenta necessária tanto por indicar um estilo participativo de gestão, quanto pela independência financeira vinculada à sua implantação (SILVA et al., 2016; JACA et al., 2012; SANTOS JUNIOR; BARBOSA; PRATES, 2012).

No Brasil, esse programa iniciou-se em filiais de organizações do Japão, em meados de 1990 e atualmente é considerado como uma ferramenta importante para introduzir à busca pela qualidade total. Desde então empresas vêm implantando o programa $5 \mathrm{~S}$ por ser simples e trazer benefícios rápidos (PEREIRA; SILVA; NOVÔA, 2016; OLIVEIRA; GOMES; ALMEIDA, 2017).

Ainda que se tenha popularizado, é frequente a constatação de fracassos resultantes de sua aplicação, muitas vezes provocados pelo desconhecimento profundo das práticas, pela falta de um plano estratégico, pela não adaptação à realidade da organização, além do tempo insuficiente para a implantação e execução das atividades. Outro ponto a ser avaliado é que embora seja simplista, um acompanhamento da implantação dos cinco sensos e auditorias frequentes precisam ser executadas para que os erros na implantação sejam evitados (RIBEIRO, 1994).

O programa 5S é conhecido no Brasil na forma dos cinco sensos, conforme identificados no Quadro 1:

Quadro 1 - Senso do Programa 5S

\begin{tabular}{|c|c|}
\hline Senso & Objetivo \\
\hline Senso de Utilização (Seiri) & $\begin{array}{c}\text { Eliminar o desnecessário, o que não está sendo } \\
\text { mais utilizado. }\end{array}$ \\
\hline Senso de Ordenação (Seiton) & Arrumar e organizar o ambiente. \\
\hline Senso de Limpeza (Seiso) & Prezar pela limpeza do ambiente. \\
\hline $\begin{array}{c}\text { Senso de Saúde e Higiene } \\
\text { (Seiketsu) }\end{array}$ & $\begin{array}{c}\text { Manter o do ambiente limpo e promoção da } \\
\text { saúde de trabalhadores. }\end{array}$ \\
\hline $\begin{array}{c}\text { Senso de Autodisciplina (Shitsuke) } \\
\text { Assimilar o programa e promover a }\end{array}$ \\
\hline
\end{tabular}

Fonte: Adaptado de Domingues (2011).

O Programa 5S pode ser implantado em diversos tipos de ambientes, não somente em empresas privadas. A implantação da ferramenta $5 \mathrm{~S}$ em uma empresa júnior se mostra de grande necessidade e importância, pois a alta concorrência vivenciada pelas pequenas e médias empresas exige uma maior qualidade em seus serviços, para que se obtenha uma vantagem competitiva, conseguindo um diferencial em seus serviços. Em empresas juniores essa realidade não é diferente, existe a necessidade de um modelo de gestão que potencialize a qualidade dos serviços. Deste modo, a utilização do Programa $5 \mathrm{~S}$ por uma empresa júnior de consultoria pode resultar em melhorias no ambiente de trabalho, promoção do bem-estar dos consultores envolvidos, melhor controle no uso de documentos, materiais, recursos e processos de trabalho. Em empresas juniores é comum se lidar com limitantes, tais como problemas de espaço, que geralmente são concedidos pela instituição de ensino superior, limitações de equipamentos, móveis e materiais. Dessa forma, é importante utilizar os recursos de forma eficiente, a fim de evitar desperdícios.

As próximas seções detalharão cada um dos sensos. 
O senso de utilização é de simples implantação e tem como objetivo a otimização do espaço, de forma a organizar o local de trabalho, reservando uma área para os materiais menos utilizados e/ou descartando materiais inúteis. Consiste na categorização dos itens de acordo com a relevância ou uso (KNECHTGES; BELL; NAGY, 2013; KAKKAR et al, 2015; LAMPREA; CARRENO; SANCHEZ, 2015).

O senso de utilização consiste na verificação de materiais, objetos, arquivos físicos e eletrônicos, e na eliminação de tudo o que for desnecessário. Embora não muito abordado, a limpeza dos arquivos eletrônicos, como dados desnecessários e arquivos que não tem mais utilidade é tão impactante quanto a otimização do espaço físico. Um número elevado de arquivos que não possuem mais função alguma pode provocar perda de tempo na busca de dados importantes ou uso de espaço eletrônico com o que já está obsoleto, ou desnecessário, comprometendo o espaço que poderia ser utilizado para armazenagem de arquivos necessários (MICHALSKA; SZEWIECZEK, 2007). A eficiência se dá pela eliminação de tudo o que não for útil para a organização (JACA et al., 2012).

Alguns procedimentos que podem ser executados e contribuem para uma melhor implantação do senso são: análise do local de trabalho; separação dos materiais úteis dos inúteis; questionamento sobre o valor do item à organização e conservação somente do que é estritamente necessário. Isto por sua vez gera economia de capital e espaço, resultando até mesmo em redução de investimentos futuros de expansão (LAMPREA; CARRENO; SANCHEZ, 2015). Por fim, tem-se que o senso de utilização estimula o emprego dos recursos de fato necessários para a organização, rejeitando os obsoletos e evitando a ociosidade dos meios úteis (JIMÉNEZ et al., 2015).

\section{Senso de ordenação - Seiton}

A ordenação é configurada no agrupamento dos materiais, utensílios, equipamentos e documentos já considerados úteis no primeiro senso, de acordo com o nível de serventia (KNECHTGES; BELL; NAGY, 2013; KAKKAR et al, 2015; LAMPREA; CARRENO; SANCHEZ, 2015).

O espaço da área de trabalho deve ser organizado de forma coerente com os materiais e seus respectivos usos. Rodrigues et al. (2014) apontam procedimentos que podem ser utilizados para executar o senso de ordenação; definir o layout da área de trabalho; ordenar os objetos semelhantes num mesmo local; utilizar etiquetas visíveis para identificar os materiais e zelar pelos materiais do local de trabalho. Assim, os itens do ambiente de trabalho devem estar dispostos de forma padronizada, com rótulos visíveis, para que os operadores possam identificar rapidamente se estão no local apropriado ou não (LEONEL, 2011).

O senso de ordenação promove diversos benefícios como a otimização do tempo, na procura de objetos, documentos e equipamentos; redução dos riscos de acidentes, com cada item em seu devido lugar; motivação e bem-estar do trabalhador; melhoria da comunicação visual e redução na movimentação (MICHALSKA; SZEWIECZEK, 2007). 
O senso de limpeza é o responsável por garantir a limpeza do ambiente de trabalho, bem como pela eliminação de qualquer poluente. Para executar o senso é necessário evitar o depósito de sujeira no ambiente, que pode se manifestar na forma de lixo, barulho ou mau cheiro. A limpeza por sua vez, deve ser realizada periodicamente, isto inclui máquinas, ferramentas, pisos e paredes, sem se esquecer de analisar as fontes de sujeira, visando eliminá-las (BITENCOURT et al., 2012; LAMPREA; CARRENO; SANCHEZ, 2015). Os novos pensamentos geram novas atitudes e a satisfação de trabalhar em um local limpo e arejado estarão visíveis e perceptíveis para cada indivíduo (SILVA et al., 2015).

A implantação do Senso de Limpeza proporciona um ambiente de trabalho mais harmônico; melhoria no trabalho em equipe e no relacionamento interpessoal; promoção do bem-estar dos envolvidos na organização e melhor conservação dos equipamentos (SILVA et al., 2015).

\section{Senso de saúde e higiene- Seiketsu}

Para a implantação desse senso é muito importante a limpeza do ambiente, sendo um dos requisitos para que a higiene prevaleça, bem como para a promoção da saúde dos colaboradores (SANTOS JUNIOR, BARBOSA e PRATES, 2012). A organização deve se preocupar com a saúde física, mental e emocional dos seus colaboradores, oferecendo um ambiente saudável de trabalho (SPIES, et al 2012; KNOREK; OLIVEIRA, 2015).

As empresas de consultoria são prestadoras de serviço que possuem o capital humano como principal ativo. Deste modo, esforços e recursos devem ser investidos para capacitar e formar os trabalhadores, o que pode resultar em alguns casos uma sensação de necessidade de retorno, cobranças e consequentemente estresse psicológico (FANTINATO, 2004).

Andrade (2001) analisou a saúde psicológica de funcionários de um banco. As principais causas de estresse levantadas pelo estudo estão relacionadas a pressão no trabalho, excesso de atividades e responsabilidades, desvalorização humana e descontentamento salarial. Como alternativas para ampliar a qualidade do trabalho do profissional, o autor sugeriu algumas práticas, tais como: atividades físicas regulares, controle alimentar, ações que estimulem e valorizem o trabalho, acompanhamento médico, entre outras. Essas práticas de exercício físico podem ser implementadas por profissionais de outras instituições.

Deste modo, este senso não está apenas relacionado a saúde física dos funcionários, mas inclui também a saúde emocional, importante principalmente para indivíduos que trabalham em atividades estressantes e sob pressão.

\section{Senso de autodisciplina- Shitsuke}

O quinto e último senso busca instituir comissões e grupos para criação e execução de modelos que auxiliem na manutenção do programa e na internalização dos demais sensos (GUPTA; JAIN, 2015). A autodisciplina está no hábito de respeitar todas as normas existentes na organização, sendo estas 
relativas aos demais sensos do programa. Espera-se que com a disciplina, os outros sensos se tornem habituais (KNOREK; OLIVEIRA, 2015; LAMPREA; CARRENO; SANCHEZ, 2015).

Durante a execução do programa, os colaboradores são incentivados a aderir aos conceitos e objetivos dos sensos. Essa adesão, quando constante, é internalizada e passa a se tornar um hábito na vida dos colaboradores da organização (KNECHTGES, BELL e NAGY, 2013). No entanto, para se assegurar o sucesso, a metodologia requer um compromisso da diretoria para incentivar comportamentos exigidos (LAMPREA; CARRENO; SANCHEZ, 2015).

As auditorias regulares revelam o status de cada senso e promovem reflexão e melhorias no programa (SILVA et al., 2015). Um sistema de recompensas também pode ser utilizado como forma de premiar funcionários mais dedicados e motivar a aderência e o cumprimento do programa (GUPTA; OLIVEIRA, 2015).

A implementação efetiva do programa 5 S numa organização costuma proporcionar melhorias interessantes na estrutura administrativa; na comunicação interna, na qualidade da ordenação de arquivos, documentos e dados; na redução de gastos financeiros e na motivação dos colaboradores, que em geral se sentem mais orgulhosos de fazerem parte de uma organização que se preocupa com a sua saúde e com o ambiente de trabalho que lhe é oferecido (DA SILVA, LIOTTO, e BRUCH, 2011). Deste modo, o programa contribui para o aumento da produtividade, diminuição de desperdícios e ampliação do bem-estar dos colaboradores (SANTOS JUNIOR; BARBOSA; PRATES, 2012).

\section{MOVIMENTO EMPRESA JÚNIOR (MEJ)}

O Movimento Empresa Júnior surgiu em 1967, quando alunos da L'École Supérieure dês Sciences Economiques et Commerciales (ESSEC) em Paris, fundaram a Junior ESSEC Conseil. O intuito da associação era conhecer de forma mais prática o mercado e suas necessidades, atuando por meio dos conceitos e ferramentas aprendidas na academia (EJFGV, 2016).

No Brasil, o Movimento se iniciou com a Empresa Júnior Getúlio Vargas (EJFGV, 2016) no final da década de 1980. Desde então o MEJ tem tomado proporções maiores. Atualmente o Brasil apresenta o maior número de empresas juniores do mundo, com 243 empresas reconhecidas pela Confederação Brasileira de Empresas Juniores (CONCENTRO, 2016).

A Brasil Junior (BJ) é a Confederação Brasileira de Empresas Juniores, que comunica as diretrizes nacionais a serem adotadas pelas federações estaduais existentes, fomenta a regulamentação das empresas juniores em âmbito nacional e se configura como um elo de colaboração e conhecimento, promovendo a integração e alinhamento entre empresas e empresários juniores do Brasil (UNE, 2016). Para a Brasil Júnior (2015), as empresas juniores são formadas por alunos devidamente matriculados em cursos de graduação da instituição de ensino superior a qual a empresa júnior está vinculada, e organizada como uma associação civil.

Uma empresa júnior (EJ) corresponde a uma associação sem fins lucrativos, que se localiza dentro da própria universidade com o objetivo de atuar com projetos no mercado de trabalho, por meio da prestação de serviços, em um 
período anterior à formatura, ou seja, criando oportunidades de aquisição de habilidades durante a formação acadêmica (BEVANGER, VISENTINI, 2016). A empresa júnior se torna um laboratório para estudantes transformarem o conhecimento adquirido na academia. Sem foco no lucro, essas associações buscam o conhecimento como moeda de troca, obtidas por meio de projetos desenvolvidos pelos alunos empresários (BATISTA et al, 2010). Deste modo, o contexto de uma EJ se torna interessante por complementar o conhecimento da sala de aula, auxiliar a inclusão do aluno no mercado de trabalho ou ainda fomentar o empreendedorismo.

\section{METODOLOGIA}

O trabalho consiste em um estudo de caso sobre a implantação do programa $5 \mathrm{~S}$ em uma empresa júnior de consultoria localizada em uma Universidade Estadual no sul da Bahia.

O problema identificado consiste na insatisfação com a ordenação de objetos, layout da sede física e a desordem na plataforma de gestão do conhecimento (Google Drive). O espaço que a empresa detém foi cedido pela universidade e não comporta todos os membros concomitantemente. Para tanto, torna-se necessário organizar a sede, bem como os projetos a serem realizados. Com o problema inicial identificado, realizou-se um estudo bibliográfico para encontrar um método que pudesse solucionar as insatisfações e que melhor se adequasse ao momento da organização. É necessário a implantação de diversas ferramentas para resolver o problema, entretanto optou-se por organizar fisicamente o núcleo da empresa por meio do Programa 5S. Com a ferramenta dos cinco sensos selecionada, criou-se um comitê formado por membros da diretoria executiva da Empresa Júnior para identificar problemas, correlacionando-os as práticas que poderiam compor o Programa 5S.

Durante a implantação do Programa, decidiu-se por realizar duas reuniões de sensibilização, para apresentação da ferramenta, objetivos, benefícios e práticas. $\mathrm{Na}$ ocasião utilizou-se um questionário para diagnosticar a atual situação da empresa. Após análise dos questionários, o comitê possuía um conjunto de informações úteis para a implantação.

Os sensos foram então implementados, com reuniões periódicas durante a implantação dos três primeiros sensos, de forma a reafirmar os valores do Programa e seus objetivos. Ao final da execução do quarto senso, a primeira equipe de auditoria foi sorteada e treinada para que pudesse executar a auditoria e então implementar o quinto senso.

\section{RESULTADOS}

Os resultados apresentarão a caracterização da empresa júnior; um diagnóstico pré-implantação, contendo uma qualificação da situação da empresa antes da implementação e uma proposta para implantação do programa.

\section{CARACTERIZACCÃO DA EMPRESA}


A empresa júnior foi fundada em 2008 e desde então presta serviços de consultoria nas áreas de gestão de estoques, elaboração de layouts e implementação de programas de qualidade no Sul da Bahia. Os serviços são geridos como projetos de consultoria, realizados em etapas, como: diagnóstico do projeto; análise da situação; a execução do projeto e a apresentação dos resultados.

A empresa está dividida nas seguintes áreas: presidência, diretoria administrativo financeira, diretoria de projetos, diretoria de marketing e diretoria de gestão de pessoas. Possui uma sede física que comporta atividades administrativas, recepção de clientes e execução dos projetos. Atualmente possui 25 colaboradores, com rotatividade anual devido ao andamento da graduação membros.

O espaço disponibilizado pela instituição não possui capacidade para comportar todos os membros ao mesmo tempo. Por conta deste motivo, há uma escala de horários, com rodízio de trabalhadores, em que se é permitido máximo três colaboradores ocupando o espaço simultaneamente. Este é um limitante na execução dos projetos.

A sede possui um computador fixo e os colaboradores utilizam seus próprios notebooks, sempre que duas mesas estejam disponíveis para tais atividades. Existem atividades que exigem que o colaborador transite pela sede, como a atualização da gestão visual dos gráficos e quadros, uso de documentação e entrega de certificados. Há também atividades que envolvem todos os integrantes e não podem ser realizadas na sede física, sendo que as diretorias precisam agendar e ocupar salas de aula da própria instituição.

Além disso, o espaço físico da empresa também deve estar sempre preparado para receber um cliente, parceiro ou mesmo um estudante e potencial membro em busca de informações. Deste modo, para que os processos sejam realizados da melhor maneira possível, é fundamental que o ambiente de trabalho seja agradável, que não comprometa as atividades a serem realizadas nos projetos já iniciados e que atenda minimamente as necessidades.

Diante desse cenário de algumas limitações, os membros da empresa perceberam a necessidade da implantação de um programa que pudesse melhor organizar a empresa e as etapas dos projetos.

\section{DIAGNÓSTICO PRÉ-IMPLANTAÇÃO DO PROGRAMA 5S}

O programa $5 S$ é adaptável à realidade da organização. Para tanto, foi realizado um mapeamento dos maiores problemas relatados pelos integrantes da empresa, a fim de correlacioná-los com ações dos cinco sensos do programa.

O diagnóstico pré-implantação foi realizado em duas etapas. Na primeira etapa foram levantadas informações sobre a organização de documentos e dos tipos de trabalho realizados na sede. Na segunda etapa ocorreu a aplicação de um formulário de avaliação da situação da empresa, com relação a ocupação do espaço físico e aos documentos arquivados (físicos e digitais). Os itens analisados pelo formulário contemplaram os três primeiros sensos, por serem de mais fácil percepção. As perguntas quanto ao senso de utilização abordavam a existência de documentos não utilizados e equipamentos e móveis sem uso. O senso de 
ordenação questionava a existência de equipamentos, documentos e materiais expostos de forma desordenada. O senso de limpeza tratou da presença de resíduos no ambiente.

Constatou-se por meio de questionário aplicado, que a empresa apresentava problemas no gerenciamento de documentação, e que arquivamento se configurava de forma ineficiente. Por meio do senso de utilização, foi relatada a presença de documentos, materiais, móveis e equipamentos sem uso e/ou desnecessários. Além disso, por meio do senso de ordenação, contatou-se que os itens e materiais eram encontrados dispostos em locais inapropriados e desordenados. Por fim, por meio do senso de limpeza, destacou-se a presença de sujeira no ambiente.

Essas inadequações, juntamente com o ambiente de pressão que uma empresa de consultoria pode apresentar, por vezes influenciavam negativamente a saúde mental dos colaboradores, que apresentavam insatisfações relacionadas ao trabalho na empresa.

Deste modo, por meio dos relatos dos colaboradores e dos dados coletados pelo questionário, observou-se a necessidade da implantação do Programa 5S, e iniciar a implantação de ferramentas internamente como forma de melhorar a qualidade do trabalho na empresa.

\section{PROPOSTA PARA IMPLANTAÇÃO DO PROGRAMA 5S}

A proposta de implantação seguiu as etapas contidas na Figura 1, que serão detalhados nas próximas seções.

Figura 1 - Fluxograma contendo a proposta de implantação

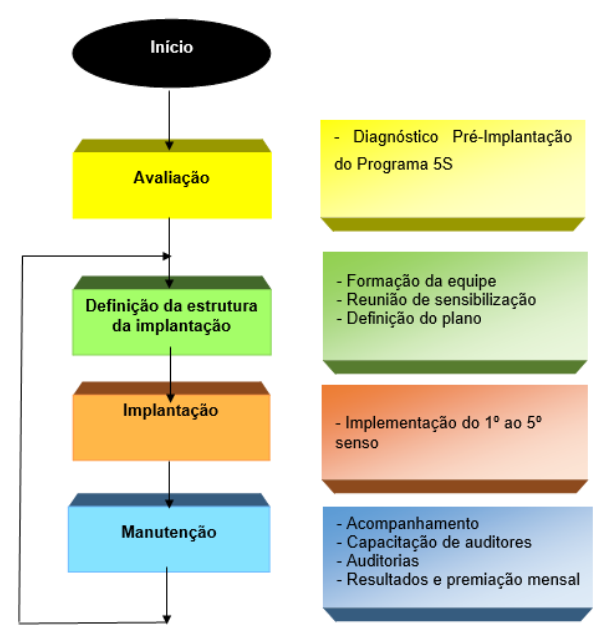

Fonte: Adaptado de Kumpel (2007).

Antes que o programa iniciasse, foi necessário avaliar a situação (avaliação) em que a empresa se encontrava. Para tanto, um questionário visando à leitura da situação atual foi realizada (Diagnóstico Pré-implantação do Programa 5S). 0 mapeamento indicou os maiores problemas percebidos pelos colaboradores. 
Para a definição da estrutura da implantação foi preciso formar equipes, realizar reunião de sensibilização e definir o plano. A equipe foi formada por meio das competências e disponibilidades dos colaboradores. Primeiramente um guardião foi selecionado, o diretor administrativo-financeiro, responsável, de acordo com o estatuto por zelar pelo patrimônio da empresa. Esse guardião possui incumbência de selecionar outras duas pessoas, que em conjunto farão parte da equipe do programa 5S. Toda a organização foi convidada para uma reunião de sensibilização, formada pela equipe do programa e pela alta administração, visando evidenciar o comprometimento com o programa (Figura 2). A reunião de sensibilização ocorreu em dois momentos, com um intervalo de dois dias para que toda a equipe pudesse comparecer e compreender o programa. Pela análise dos questionários elaborou-se um plano de execução do Programa 5S para a Empresa Júnior. O processo de implantação se deu pela aplicação do primeiro ao quinto senso.

Figura 2 - Workshop sobre o programa 5S

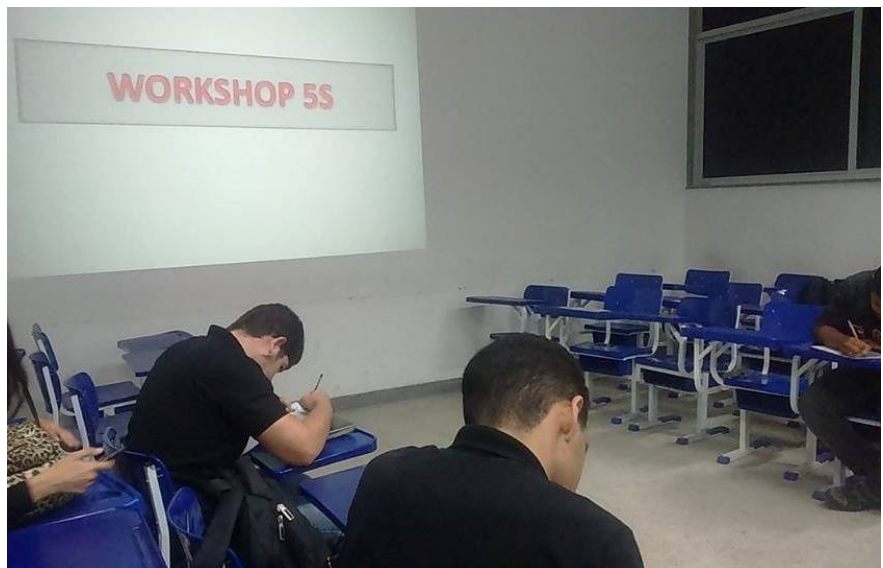

Fonte: Autoria própria (2017).

No primeiro senso, o de descarte o comitê do programa foi responsável por organizar o "Mutirão do 1오", em que todos os bens da empresa júnior foram analisados e avaliados quanto ao uso. Ao identificar bens que não eram mais utilizados, optou-se por descartá-los. Os documentos e certificados que não faziam parte do patrimônio da empresa ou com data superior a cinco anos, (período em que própria universidade estipula para arquivamento de documentos) também foram descartados. Além disso, equipamentos eletrônicos como teclado, mouse e duas impressoras fora das condições de uso foram devidamente descartadas, em espaço indicado na instituição, já que precisam ser recolhidos e não podem ser descartados em lixo comum. Materiais de papelaria impróprios ao uso foram descartados. Os bens com pouco uso foram reservados para alocação ideal no próximo senso. Os documentos na plataforma online, Google Drive, sem uso também foram excluídos e descartados permanentemente.

No segundo senso, o da organização, os materiais e documentos dentro da sede física foram ordenados, catalogados por meio de etiquetas e realocados de acordo com a frequência do uso e com o tipo de material. Os documentos, materiais e equipamentos que ficaram dispostos no gaveteiro foram organizados em categorias. A primeira gaveta foi utilizada pelas pastas dos setores da empresa, 
a cada setor foi atribuída uma cor de pasta para facilitar e também ordenadas alfabeticamente, para ser de mais fácil visualização e evitar desordem (Figura 3).

Figura 3 - Primeira gaveta: antes e depois de ordenação

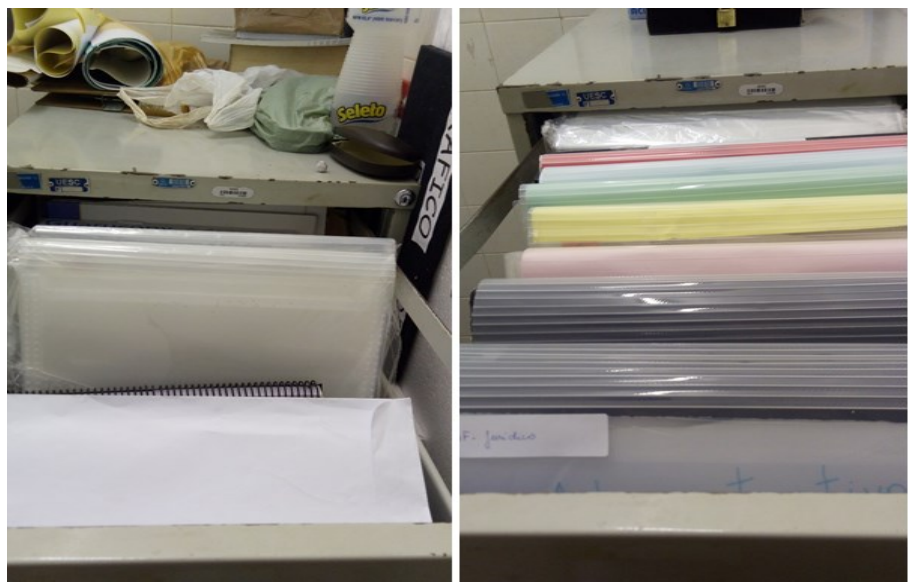

Fonte: Autoria própria (2017).

A segunda gaveta foi ocupada com os materiais de papelaria, a terceira com equipamentos e livros (Figura 4), e a quarta com materiais com uso de menor frequência, como uniforme de times (utilizado em momentos de integração da empresa), bandeira da empresa e toalhas de mesa para eventos.

Figura 4 - Terceira gaveta: antes e depois do senso de ordenação
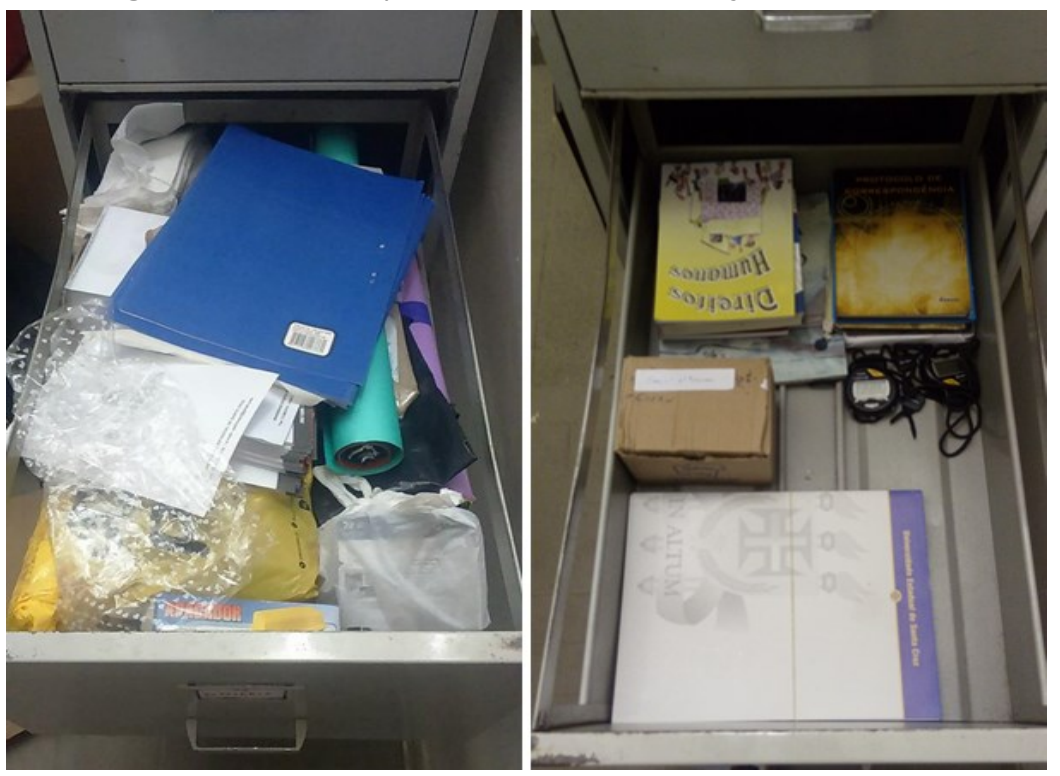

Fonte: Autoria própria (2017).

A sala de "estoque", conhecida por ser o local em que os itens sem uso eram armazenados foi limpa, esse espaço possui a encanação do prédio e não é ventilado, além de muito pequeno, não sendo um espaço ideal para o trabalho, mas não excluído, por ser um bom local para o gaveteiro de arquivos, documentos e materiais. Anteriormente, essa sala era utilizada como estoque de materiais e móveis totalmente inutilizados (Figura 5). 
Figura 5 - Sala sem ventilação: antes e depois

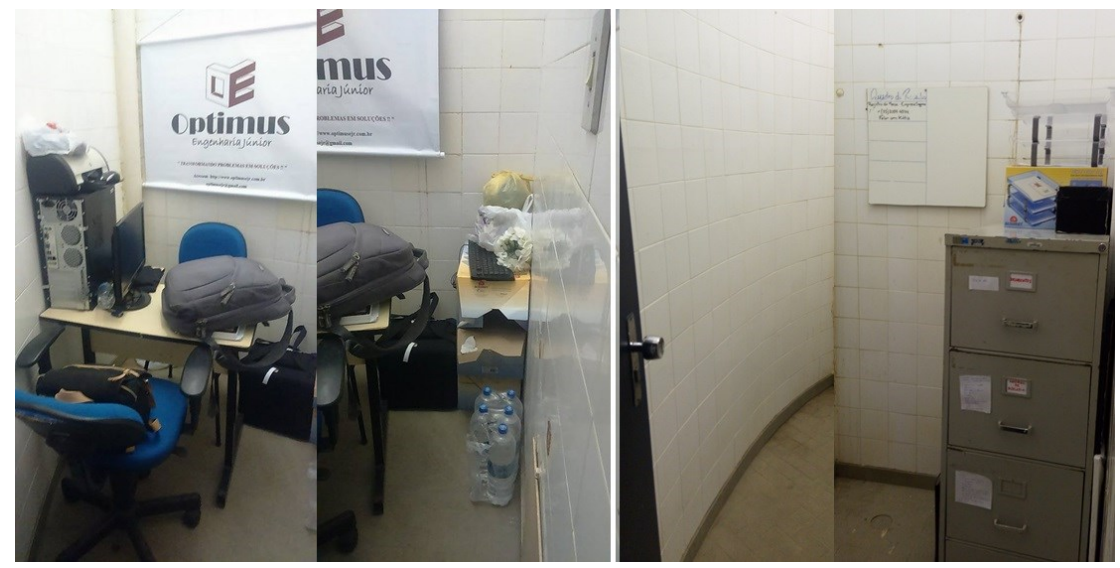

Fonte: Autoria própria (2017).

As cadeiras e mesa que lá ficavam sem uso efetivo foram retiradas e foi incorporado um gaveteiro. Os pertences dos membros foram colocados em espaço reservado para bolsas e mochilas. Essa mudança permitiu o aumento do número de trabalhadores simultâneos no espaço (Figura 6).

Figura 6 - Novo espaço de trabalho

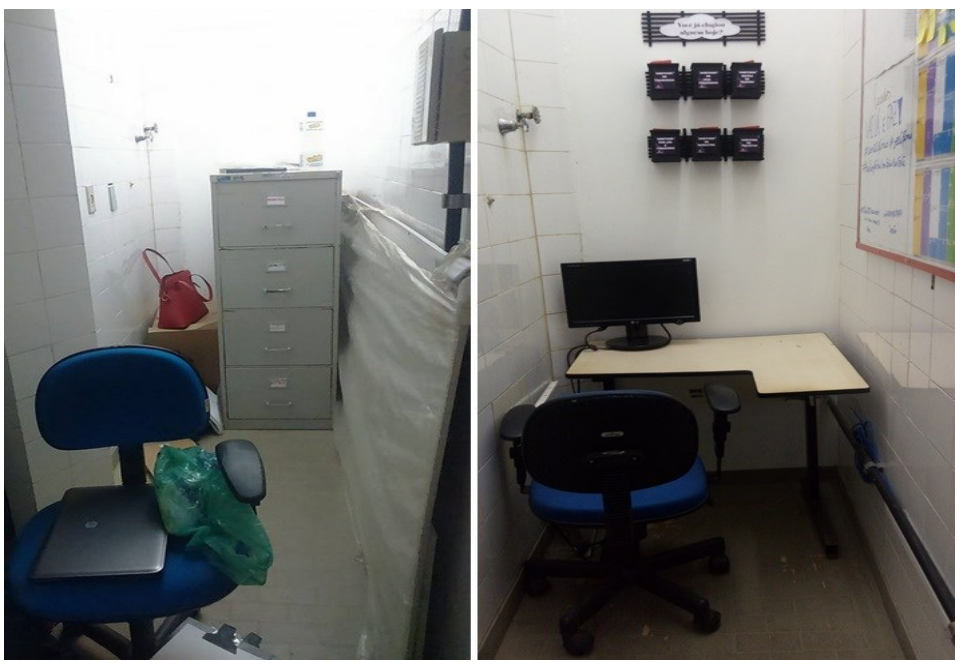

Fonte: Autoria própria (2017).

Materiais utilizados em confraternizações da equipe (copos, talheres, pratos e guardanapos), que antes ficavam no gaveteiro, foram reunidos em uma caixa e dispostos sobre o frigobar.

Passou-se a utilizar uma bandeja etiquetada para recebimento de documentos de qualquer setor e também por qualquer integrante, necessitando apenas que o receptor o coloque em local indicado.

Os documentos e arquivos online, situados no Google Drive da empresa, foram separados por ano, uma vez que cada um configura uma gestão diferente, e agrupados por setores. Além disso, passou-se a utilizar na caixa de entrada do email geral da empresa júnior os marcadores específicos para os setores e ações.

Para o terceiro senso, o de limpeza, definiu-se uma rotina de limpeza e arrumação que ficou disponível e visível em um quadro na empresa. 
Anteriormente esta tarefa ficava sob responsabilidade de uma equipe de limpeza da universidade. Com o rearranjo promovido por esse senso, criou-se uma lista de verificações contendo a data e horário da limpeza promovida pela equipe da universidade e a arrumação realizada pelos membros internos.

No quarto senso, o senso de saúde, os desejos do colaborador passaram a ser considerados. Para isso, as relações interpessoais foram estimuladas por meio da avaliação mensal do setor de gestão de pessoas. Nessas avaliações cada membro informou problemas e sugestões para melhorar a qualidade do seu trabalho. A saúde psicológica também deve ser analisada, uma vez que em empresas de consultoria a pressão e mal-estar psicológicos são relatados com maior frequência na literatura. Para suprir essa necessidade, o apoio psicológico foi sugerido ao setor de gestão de pessoas, por meio de uma parceria com um curso de psicologia, a fim de promover um acompanhamento periódico dos membros efetivos da empresa. Ações de atividades físicas começaram a ser estimuladas mensalmente. Outra prática adotada foi a de um painel de elogios anônimos e no fim de cada mês são comemorados os aniversários dos componentes da empresa, visando maior integração entre as pessoas.

O quinto senso, a autodisciplina foi fomentada pela continuidade efetiva do programa, por meio da planilha para auditorias e política de recompensas do programa. Dois auditores sorteados foram os responsáveis por realizar a auditoria por mês, e capacitados para realizar a auditoria.

Para manutenção do Programa criou-se um roteiro - o monitoramento rotineiro. O monitoramento se deu por meio de um guardião do programa, necessário para realizar ajustes quando necessários e manter o programa em continuidade e execução. $O$ guardião é responsável por averiguar periodicamente a necessidade de alteração do programa, além de checar a satisfação dos membros. No início de cada mês, os auditores foram sorteados e recebiam do guardião do programa, os repasses das diretrizes da auditoria, bem como uma breve explicação sobre o programa e sua importância. A intenção consiste na internalização das diretrizes do programa.

Para as auditorias, os membros foram avaliados de acordo com o cumprimento do programa na sede da empresa júnior. Ao final da implementação do quinto senso, uma planilha foi disponibilizada, para que os colaboradores (divididos por turnos) preenchessem caso algo atípico ocorresse. A sede também passou por avaliação, sem data agendada, além da ferramenta de gestão da informação, o Google drive. A planilha de auditoria está demonstrada na Figura 7, em que todo o processo foi convertido em uma pontuação para a empresa. 
Figura 6 - Planilha de auditoria

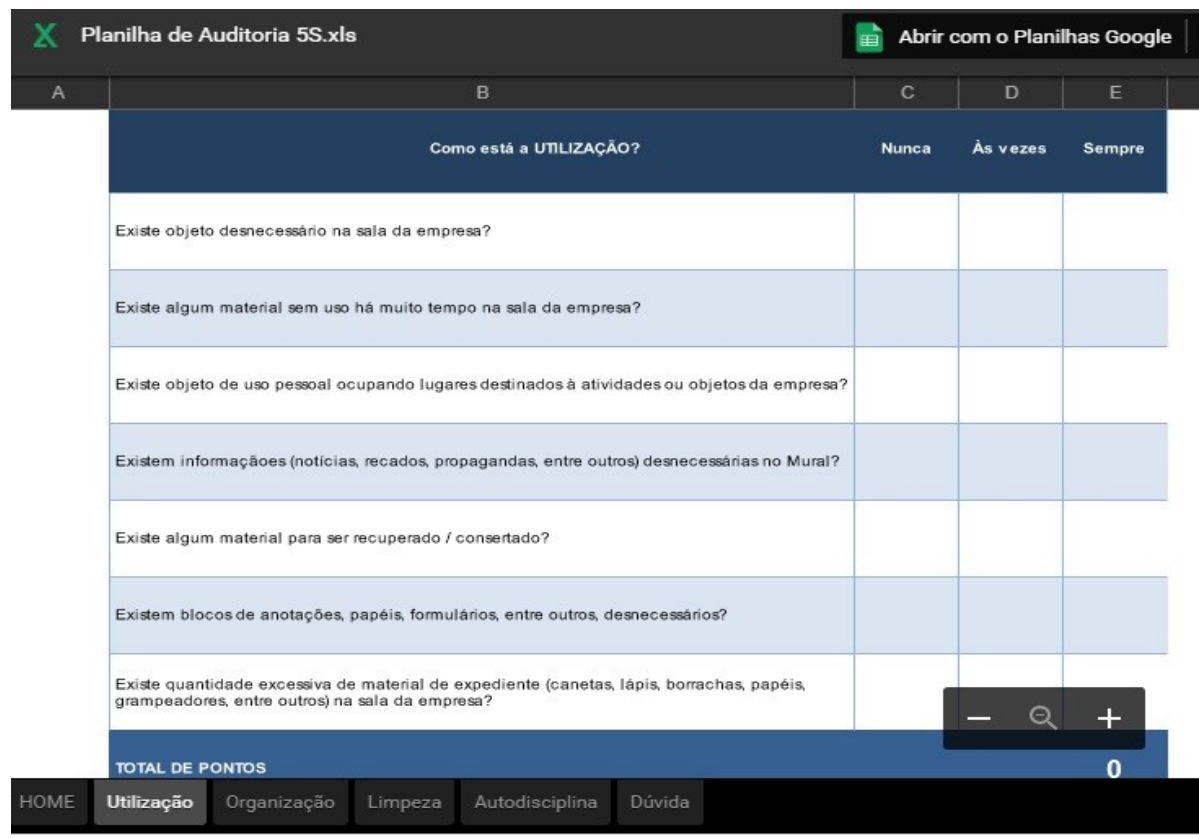

Fonte: Autoria própria (2017).

As auditorias geraram notas de qualificação da equipe, além de demonstrar as falhas e os setores envolvidos, com três categorias de premiação: medalha de bronze, que corresponde ao custeio pela empresa de refrigerantes e sucos ao final de cada mês, caso se atinja a meta de $60 \%$ a $75 \%$ do programa; medalha de prata, com a premiação de uma semana de cafezinho aos membros com direito a biscoito e café ao se atingir a meta de $75 \%$ a $90 \%$ no mês e, por fim, a medalha de ouro, em que a empresa custearia o bolo dos aniversariantes do mês, ao se atingir uma meta superior à $90 \%$ dos critérios de auditoria do programa. Embora a premiação seja relativamente simples, serve como um incentivo a equipe e reconhecimento tanto do trabalho, quanto da importância do Programa 5S.

\section{CONSIDERAÇÕES FINAISS}

Por meio desta pesquisa, o Programa 5 S foi implantado em uma empresa júnior de engenharia de produção. Foi realizada uma análise do ambiente empresarial júnior, em que a situação da empresa se encontrava e os maiores problemas relatados pelos colaboradores. Dessa forma, a implantação do programa foi planejada e realizada.

Com a implantação, foi possível perceber que o ambiente de trabalho ficou mais agradável e livre de documentos que ocupavam o pouco espaço disponível da empresa. Os documentos foram catalogados e ordenados alfabeticamente, passando a ser encontrados com mais facilidade. $O$ espaço melhor utilizado permitiu que mais um trabalhador passasse a ocupar o espaço interno da empresa (quatro indivíduos) simultaneamente.

Ao fim da execução de todos os sensos, uma pesquisa de satisfação foi realizada com os 24 membros, na qual foi possível constatar que $37,7 \%$ dos membros da empresa se consideram totalmente satisfeitos com o programa 5S, $50 \%$ sinalizaram estarem satisfeitos, $12,5 \%$ consideram-se parcialmente satisfeitos 
e nenhum membro se considerou insatisfeito ou totalmente insatisfeito. Ainda por meio da pesquisa, pode-se elencar algumas sugestões como: manter auditorias mais frequentes no início; ampliar a cobrança da organização do espaço físico; promover verificação mensal para constatar se senso de saúde está sendo suficiente para atender as necessidades da empresa; entre outras. Novas sugestões foram coletadas a cada auditoria, durante o monitoramento rotineiro proposto, como alternativa para promover a melhoria contínua.

Embora as ações do programa sejam simples, esta foi a primeira implantação de uma ferramenta de gestão na empresa, e que trouxe resultados reais na execução dos trabalhos, servindo como um treinamento para a implantação de outras ferramentas de gestão no futuro. 


\title{
Implementation of $5 \mathrm{~S}$ program in a junior consulting company
}

\author{
ABSTRACT
}

The competitiveness between companies fosters the need for practices in total quality management to effectively meet the needs of its customers and also of its employees. A junior consulting company also needs to stay active in the market. For this reason, quality practices are necessary. The 5S Program is considered an appropriate methodology for initiating and implementing the inclusion of quality programs in an organization, aimed at improving the work environment, increasing productivity and managing documents and materials. The objective of the study is to implement the $5 \mathrm{~S}$ program in a junior consulting firm at the State University in the south of Bahia. In order to do so, it was necessary to analyze the company's environment and perform a diagnosis of its needs, in addition to planning and executing the 5 S Program, evaluating the process and suggesting possible improvements. The implementation of the Program took place in stages and began with the presentation of the theme to the members through a workshop, later the five senses were put into practice and then periodic audits were carried out to follow the development of the senses. At the end of the first audit, a satisfaction survey was conducted, which identified that $87.5 \%$ of the members were satisfied with the implementation of the program in the junior company.

KEYWORDS: Total Quality Management. 5S Program. Junior Company. 
REFERÊNCIAS

ANDRADE, A. Ocorrência e controle subjetivo do stress na percepção de bancários ativos e sedentários; a importância do sujeito na relação "atividade física e saúde". 280f. Tese (Doutorado em Engenharia de Produção) Universidade Federal de Santa Catarina, Florianópolis, 2001.

BATISTA, M. K., BITENCOURT, B. M., SILVA, F. M., RUAS, R. L. Empresa Júnior: Onde a Moeda de Troca é o Conhecimento. In: XXXIV ENCONTRO DAANPAD, 2010, Rio de Janeiro. Anais. Rio de Janeiro: ENANPAD, 2010.

BRASIL JÚNIOR. Estatuto da Confederação Brasileira de Empresas Juniores. Disponível em:

https://www.brasiljunior.org.br/uploads/institutional/file/file/8/Estatuto_BJ_201 5.pdf. Acesso em julho de 2017.

BEVANGER, E.; VISENTINI, M. S. Publicações científicas brasileiras sobre empresas juniores na área de administração: um estudo bibliométrico. REGE - Revista de Gestão, 23, 197-210, 2016.

BIGLIARDI, B; GALATI, F. The Implementation of TQM in R \& D Environments, Journal of Technology Management \& Innovation,vol.9, no.2, Santiago, 2014.

BITENCOURT, C. V.; MARINS, C. S.; SOUZA, D. O.; RAMOS, R. R. Análise dos Resultados Obtidos por meio da Implantação Parcial do Programa $5 \mathrm{~S}$ em uma Empresa Metalúrgica de Barra Mansa. Simpósio de Excelência em Gestão e Tecnologia- IX SEGET, 2012.

CARVALHO, M. M.; PALADINI, E. P. Gestão da qualidade: teoria e casos. Rio de Janeiro: Elsevier, 2005.

CONCENTRO. Gerador de Projetos. Disponível em:

http://www.concentro.org.br/. Acesso em dezembro de 2016.

DA SILVA, L.; LIOTTO, L.; BRUCH, V. A implantação e utilização do Programa 5s numa empresa familiar de médio porte. PERSPECTIVA, Erechim. v.35, n.132, p.107-118, 2011.

DOMINGUES, M.A. A Importância do Programa 5s para a Implantação de um Sistema da Qualidade. 41 f. Monografia (Pós-Graduação em Gestão de Negocios) - Universidade Federal do Paraná, Curitiba, 2011. 
EJFGV. Empresa Júnior Fundação Getúlio Vargas, 2016. Disponível em: http://ejfgv.com/. Acesso em dezembro de 2016.

FANTINATO, O. et al. Indicadores biopsicossociais na responsabilidade socioambiental: relações possíveis. In: SERVIÇO SOCIAL DA INDÚSTRIA. DEPARTAMENTO NACIONAL. Seminários Responsabilidade Social e Qualidade de Vida no Trabalho: coletânea de textos. Brasília: SESI/DN, 2004.

GONZALEZ, R. V. D.; MARTINS, M. F. Competências habilitadoras da melhoria contínua: estudo de casos em empresas do setor automobilístico e de bens de capital. Gestão\&Produção, vol.22, n.4, pp.725- 742, 2015. crossref

GUPTA, S.; JAIN, S. K. An application of 5 S concept to organize the workplace at a scientific instruments manufacturing company", International Journal of Lean Six Sigma, Vol. 6 Issue: 1, pp.73-88, 2015.

JACA, C.; VILES, E.; MATEO, R.; SANTOS, J. Components of sustainable improvement systems: theory and practice. The TQM Journal., 24(2), 142-154, 2012. cross ref

JIMÉNEZ, M.; ROMERO, L.; DOMÍNGUEZ, M.; ESPINOSA, M. D. M. 5S methodology implementation in the laboratories of an industrial engineering university school. Safety Science, v. 78, p. 163-172, 2015. crossref

JURAN, J. M. A qualidade desde o projeto. São Paulo : Pioneira, 1997.

KAKKAR, V.; DALAL, V.S; CHORARIA, V.; PARETA, A.S.; BHATIA, A. Implementation Of $5 S$ Quality Tool In Manufacturing Company: A Case Study. International Journal of Scientific \& Technology Research, Volume 4, Issue 02, 2015.

KNECHTGES, P.; BELL, C. J.; NAGY, P. Utilizing the 5 S Methodology for Radiology Workstation Design: Applying Lean Process Improvement Methods. Journal of the American College of Radiology. v. 10, n. 8, p. 633-634, 2013. crossref

KNOREK, R.; OLIVEIRA, J. P. Gestão do Agronegócio: Implantação do Sistema De Qualidade Total Utilizando o Programa 5s na Indústria Ervateira. Revista de Administração Geral - RAG, v.1, no 1, 2015.

KÜMPEL, Lidiane. Implantação do Programa 5S para melhoria de qualidade em uma indústria moveleira. Monografia final do curso de Engenharia de Produção. Centro de Tecnologia da Universidade estadual de Maringá. Paraná, 2007. 
LAMPREA, E. J. H.; CARRENO, Z. M. C.; SANCHEZ, P. M. T. M. Impact of $5 S$ on productivity, quality, organizational climate and industrial safety in Caucho Metal Ltda. Ingeniare. Revista chilena de ingeniería, vol. 23 № 1, pp. 107-117, 2015.

LEONEL, J. C. R. R. P. O Programa 5 S e sua aplicação em uma fábrica de embalagens de papel. Monografia (Graduação em Engenharia de Produção) Universidade Federal de Juiz de Fora, Juiz de Fora, 2011.

MARSHALL JUNIOR, Isnard et al. Gestão da qualidade. Rio de Janeiro: Editora FGV, 2010.

MICHALSKA, J.; SZEWIECZEK, D. The 5 S methodology as a tool for improving the organisation. Journal of Achievements in Materials and Manufacturing Engineering 24 (2): 211-14, 2007.

MILNITZ, D.; TUBINO, D. F. Construção de uma escala para medir o nível dos colaboradores para a prática da Melhoria Contínua em uma organização por meio do modelo de resposta nominal da TRI. Production, 2016, vol.26, n.3, pp.581-589, 2016.

OPRIME, P. C.; MONSANTO, R.; DONADONE, J. C. Análise da complexidade, estratégias e aprendizagem em projetos de melhoria contínua: estudos de caso em empresas brasileiras. Gestão\&Produção, vol.17, n.4, pp.669-682, 2010.

\section{crossref}

PEREIRA, D. O.; SILVA, H. A; NOVÔA, N. F. Implantação do Programa 5 S em uma empresa júnior: estudo de caso da Ello Empresa Jr. Scientia Tec: Revista de Educação, Ciência e Tecnologia do IFRS - Campus Porto Alegre, , v.3, n.1, p. 116140, 2016.

RIBEIRO, H. 5S A Base para a Qualidade Total: um roteiro para uma implantação bem sucedida. Salvador: Casa da Qualidade, 115 p., 1994.

RODRIGUES, F. S.; SILVA, D. L.; LIMA, V. R.; BAGNO, R. B. 5S Como Programa De Melhoria: Proposta De Implantação Em Uma Indústria De Painéis Elétricos. Sinapse Múltipla, v. 3, no 1, 2014.

SANTOS JUNIOR, P. A.; BARBOSA, J. C.; PRATES, G. A. IMPLEMENTAÇÃO DE UM SISTEMA 5S EM EMPRESA DO RAMO MOVELEIRO LOCALIZADA NA REGIÃO DE ITAPEVA-SP. Qualitas Revista Eletrônica, v. 13, n.1, 2012. 
SILVA, A. L. E.; REIS, L. V.; SANTOS, L. M. A. L; SANDIM, M.; PEREIRA, Z. I. S. Percepção e análise do programa $5 \mathrm{~S}$ em uma empresa prestadora de serviço. Revista GEPROS, v. 11, n. 3, 2016.

SPIES, B. R.; FORNARI, C.; BELLAVER, I.; MEINERZ, N. C.; COSTA, T. H. C. Implantação do programa $5 \mathrm{~S}$ em uma indústria de alimentos (Estudo de Caso). In: SIMPÓSIO DE ENGENHARIA DE PRODUÇÃO, n. 19, 2012, Bauru. Anais... Bauru: SIMPEP, 2012

TANAKA, W.Y.; MUNIZ JÚNIOR, J.; FARIA NETO, A. Fatores Críticos para Implantação de Projetos de Melhoria Contínua segundo Líderes e Consultores Industriais. Revista Eletrônica Sistemas \& Gestão, no7, p. 103-121, 2012.

VIEIRA, A. M.; GALDAMEZ, V. C.; SOUZA, F. B.; OLIVEIRA, O. J. Diretrizes para desenvolvimento coletivo de melhoria contínua em arranjos produtivos locais. Gestão\&Produção, vol.20, no2, 2013. crossref

Recebido: 21 jul. 2017

Aprovado: $05 \mathrm{dez} .2017$

DOI: 10.3895/gi.v13n3.6739

Como citar:

BARBOSA, V. C. S.; OLIVEIRA, M. R. Implantação do programa 5 s em uma empresa júnior de consultoria. R. Gest. Industr., Ponta Grossa, v. 13, n. 3, p. 01-21, set./nov. 2017. Disponível em:

<https://periodicos.utfpr.edu.br/rgi>. Acesso em: XXX.

Correspondência:

Virnna Cristhielle Santana Barbosa

Rua Santa Cruz, Vila Santa Cruz, 130, apartamento 02, Montes Claros, Minas Gerais, Brasil.

Direito autoral: Este artigo está licenciado sob os termos da Licença Creative Commons-Atribuição 4.0

Internacional. 